\title{
El movimiento de mujeres y las luchas sociales por la democratización en la Nicaragua postrevolucionaria $(1990-2010)$
}

\section{Armando Chaguaceda"}

Recibido: junio de 2010 / Aceptado: julio de 2010

El trabajo aborda los antecedentes históricos y los elementos organizativos, identitarios e ideológicos que caracterizan al movimiento de mujeres en la Nicaragua postrevolucionaria (1990 2010). Se describe su desarrollo en relación con una agenda democratizadora de la política y sociedad nicaragüenses, en las coordenadas abiertas tras el fin de la Revolución Sandinista y a partir de la compleja (y convulsa) situación de una Nicaragua inmersa en la transición y consolidación de un modelo neoliberal y la persistencia de prácticas políticas tradicionales.

Palabras clave: Movimiento de mujeres / Nicaragua/Lucha Social/Democratización

(...) Sólo las luchas - a la vez politicas, sociales y culturales- pueden abrir el horizonte hacia nuevos escenarios politicos y, por ende, a la posibilidad de una redistribución del poder social (Svampa, 2008, p. 24).

\section{Introducción ${ }^{1}$}

Nicaragua es un país de ricas tradiciones de organización y movilización sociales, ligadas a ciclos de modernización y conflicto vinculados con el ejercicio o confrontación

Politólogo e historiador, miembro del Observatorio Social de América Latina y Coordinador del Grupo de Trabajo Anticapitalismo $\mathcal{E}$ Sociabilidades Emergentes del Consejo Latinoamericano de Ciencias Sociales (CLACSO). Correo electrónico: xarchano@gmail.com

1 Este texto introduce resultados parciales de una investigación comparada sobre movimientos sociales autónomos y su relación con la política gubernamental, realizada en países enclavados dentro de la Alternativa Bolivariana para las Américas (ALBA). 
del poder estatal. En la Constitución vigente -aprobada en las postrimerías de la época revolucionaria (1987)- Nicaragua es definida como una república democrática, participativa y representativa (título 2, sobre el Estado, capítulo único, art. 7), en la cual la soberanía reside en el pueblo (título 1, capítulo único, art. 4) que la ejerce a través de instrumentos democráticos y el estado debe garantizar y promover los avances sociales y políticos dirigidos al bien común (art. 4). También se reconoce el pluralismo político y la existencia y participación de las organizaciones políticas en asuntos nacionales sin restricción ideológica (art 5). Los ciudadanos tienen derecho a participar en igualdad de condiciones en los asuntos públicos y la gestión estatal (cap. II, art 50), y hacer peticiones, denuncias y críticas al Estado (art 52) (Asamblea Nacional, 2010).

Lo anterior establece el marco formal por el cual, mediante lo estipulado en legislación complementaria, la ciudadanía organizada puede incidir en la arena pública a través de las organizaciones y movimientos de la sociedad civil (en adelante SC). Las organizaciones de mujeres adquieren inusual protagonismo y beligerancia desde hace dos décadas, ligadas a las luchas por sus derechos y enfrentadas a la conservadurización de la agenda sociopolítica de los actores políticos nacionales. En este trabajo se abordan los elementos (organizativos, identitarios, ideológicos) que caracterizan dicho movimiento y su desarrollo en relación con una agenda democratizadora de la política y sociedad nicaragüenses, en las coordenadas abiertas tras el fin de la Revolución Sandinista y a partir de la compleja (y convulsa) situación de una Nicaragua inmersa en la transición y consolidación de un modelo neoliberal.

\section{Presupuestos teóricos}

Toda sociedad abarca un conjunto de actores (asociaciones, grupos informales y ciudadanos individuales) que participan cotidianamente en la conformación y reconfiguración de las relaciones dentro de los disímiles espacios sociales, así como en los procesos de interacción sociedad-Estado. Estos actores poseen sus propias estrategias y capacidad de incidencia, integrando diversos tipos de alianzas estables y formales o informales y coyunturales, cuya suma permitiría considerar a la sociedad, en toda su pluralidad y extensión, el factor instituyente de la democracia por encima de los arreglos institucionales específicos (Cansino, 2010, p. 18).

La vida social se teje a partir de la interacción concreta entre individuos y subjetividades colectivas dotadas con diversos niveles de identidad y organización y relativamente descentralizadas. Estas identidades colectivas son tejidas por la práctica, las memorias compartidas, las rutinas y usos de la vida cotidiana en constante reinvención. Podemos diferenciar dentro de éstas aquellas identidades adscriptivas (género, etnia, clase) y otras de índole electiva (organizaciones, movimientos) (Domingues, 2009, pp. 163-170). El movimiento de mujeres constituye un cruce de identidades diversas de ambos tipos que a partir de cierto nivel de sistematización y elaboración, socializan un discurso feminista(s).

Para el estudio del fenómeno es útil recordar cómo el pensamiento sociológico de matriz posthabermasiana (con Andrew Arato y Jean Cohen a la cabeza) distingue tres ámbitos o esferas que se diferencian cualitativamente 
entre sí dentro del entramado social: el Estado, orientado por el poder políticoadministrativo; el mercado, regido por el factor dinero y la SC, no estructurada por lógicas de dominación política o intercambio económico o mercantil, sino por relaciones culturales de cooperación, solidaridad, amistad y otras semejantes. Este enfoque destaca que ni el Estado ni el mercado pueden, por sí mismos, asumir las funciones de integración social, pues estas funciones quedan a cargo del conjunto de instituciones sociales que reproducen los valores culturales y las formas de vida de una sociedad a través de prácticas de entendimiento mutuo que construyen las bases de la solidaridad y la cooperación entre individuos.

Cualquier definición reunirá una tensión entre lo descriptivo (la SC como realmente es) y lo normativo (como debe o aspira ser). Aunque se reconozca su diversidad y heterogeneidad, implícitamente suele asumirse la existencia de una cierta coherencia y misión de la SC como esfera conformada por organizaciones (en adelante OSC) y movimientos que poseen, como norma, fines no lucrativos, dependen materialmente de recursos externos (públicos y/o privados) y del autofinanciamiento, emplean profusamente el voluntariado y producen bienes relacionales colectivos. Se trata de actores que hacen incidencia en diversas políticas públicas y apelan a la solidaridad, pese a lo cual no escapan de procesos negativos como la burocratización.

Siguiendo esa lectura se postula que una moderna SC debe reunir rasgos como la pluralidad (conectando grupos humanos diversos), la publicidad (al expandir instituciones culturales y comunicativas), la legalidad (por promover formas y principios generales que demarcan su espacio de actuación frente a la economía y el Estado) y la individualidad (como campo para el despliegue de la autodeterminación y desarrollo personales (Arato \& Cohen, 2002). En tanto espacio social diferenciado y complementario a los estatales y mercantiles, la SC debe contribuir a la formación de la opinión pública, a establecer redes de colaboración en las tareas del gobierno y difundir diversos valores cívicos y políticos, en una permanente tensión entre lo normativo y lo fáctico, entre el potencial democratizador y aquellos valores y prácticas tradicionales presentes en el entorno social y que sus mismas organizaciones reproducen.

Según esa tradición teórica, los actores que conforman la SC se (auto) organizan en torno a dos principios de acción colectiva: la autonomía y la autolimitación (Arato \& Cohen, 2000). La autonomía se refiere a la abierta diferenciación de la SC frente al Estado y al mercado, mientras que la autolimitación establece que el fin y los objetivos de las acciones no se guían por la búsqueda del poder o la integración al Estado, sino por apuntar a una reforma radical de la vida pública. La naturaleza del contexto nicaragüense y los conflictos que allí se desarrollan hacen particularmente central la defensa de la autonomía de los actores de la SC (y en especial del movimiento de mujeres) frente a la injerencia de los coludidos poderes políticos, empresariales y eclesiales, cuyo accionar siempre ha tendido al control, la cooptación o supresión de las voces críticas.

Los actores de la SC poseen diferentes tamaños, niveles de organización y lógicas de funcionamiento, a partir de los cuales se insertan en contextos espaciotemporales disímiles y desempeñan roles políticos divergentes, tanto democráticos como autoritarios. El grado de desarrollo de cualquier SC está determinado por 
varios factores: existencia de una cultura y tradición asociacionista; disposición de leyes y políticas estatales que garanticen su desarrollo; vitalidad de la ciudadanía, grado de autoorganización de los grupos, etc. Semejante heterogeneidad y diversidad de elementos también es un factor presente y visible en el movimiento de mujeres nicaragüense.

La SC continúa siendo un lugar de luchas culturales, de interpretación, inclusión y exclusión, de pugnas por la hegemonía. No le corresponde una lógica única, abstracta e internamente indiferenciada. Aunque ciertos discursos la representan como un sujeto homogéneo y cuasi universal -la sociedad civil nacional o global- en tanto comunidad ciudadana formada a partir de la reunión de grupos e individuos disímiles, supuestamente abocados a la consecución del bien común, no puede ignorarse que la heterogeneidad de formatos organizativos, identitarios e ideológicos de la SC es un hecho sociológico y político visible. La tensión entre un oenegismo profesionalizante y un activismo de corte movimientista, con toda su secuela organizativa, ideológica y material, es una expresión de dicha heterogeneidad particularmente visible dentro del movimiento de mujeres nicaragüense.

Tampoco la separación analítica que demarca las organizaciones de la sociedad civil (OSC o movimientos sociales) de aquellas de la sociedad política (partidos) resulta siempre adecuada para comprender los procesos reales. La definición del espacio social en campos o esferas donde los sujetos se relacionan alrededor de una serie de bienes sociales y en los que su distribución se traduce en disputas, es una distinción analítica. La decisión de una OSC o movimiento, de actuar políticamente, involucrándose en una coyuntura electoral, no implica necesariamente que se esté dando una transformación cualitativa en sus objetivos ni en sus relaciones con los ámbitos sociales en los cuales está inserto. La relación y accionar actuales del movimiento de mujeres, en el marco de la contienda por las venideras elecciones presidenciales son reveladores de estas fronteras móviles y porosas.

Para comprender las luchas concretas en las que las organizaciones sociales se inscriben es útil conocer los proyectos políticos con los que aquellas se identifican. Los proyectos políticos son construcciones simbólicas que mantienen relaciones cruciales con culturas políticas e ideologías particulares. Los actores que formulan y difunden los proyectos políticos expresan, por un lado, un aprendizaje normativo e impulsan nuevos principios culturales; y por otro, con frecuencia reproducen, especialmente en sus prácticas concretas, peculiares combinaciones de culturas políticas que muestran la coexistencia y la tensión entre los nuevos y los viejos principios culturales.

En América Latina ha sido destacada la confluencia y contraposición de actores adscritos a los proyectos neoliberal, autoritario y democrático participativo (Dagnino, Olvera \& Panfichi, 2006). Entre los actores que han mostrado especial creatividad y beligerancia por expandir a nivel regional los marcos de la política moderna (impulsando procesos democratizadores y participativos) e innovar discursiva y prácticamente, destacan los movimientos feministas o, en un sentido más amplio, las luchas de mujeres organizadas. En ese sentido, Nicaragua no constituye una excepción.

En este texto identificamos de forma genérica como "movimiento de mujeres" al segmento de la SC nicaragüense que reúne diversos grupos, formas de pensar y 
campos de acción dirigidos a la defensa y promoción de los derechos de las mujeres, y que sostiene (en sus plurales visiones) la autonomía e identidad femenina ${ }^{2}$ como eje de acción de sus organizaciones y grupos (Cuadra \& Jiménez, 2009, pp. 5-6). Hablamos de un campo atravesado por contradicciones y desigualdades, tanto en las agendas políticas como en los niveles de madurez y/o separación alcanzados respecto a los actores dominantes en el sistema político, la economía y la sociedad nacionales. Pero que en conjunto se ha destacado por su beligerancia en comparación con el accionar de otros movimientos, organizaciones e incluso partidos políticos. ${ }^{3}$

Diversos colectivos y activistas dentro del movimiento de mujeres privilegian en sus declaraciones y acciones un conjunto de elementos que resultan sustanciales para la condición democrática: respeto y promoción de libertad personal y justicia social, protección a minorías y grupos vulnerables, defensa de los derechos humanos en su integralidad, entre otros. Se trata de asuntos relevantes y coherentes con nuestra visión multidimensional de la democracia, a la que concebimos como la conjunción de un ideal normativo, un proceso socio-histórico y un régimen político (suma de valores, prácticas y reglas institucionalizados) que garantizan y hacen efectivos los derechos, la participación y la representación de la ciudadanía en un contexto dado. En este trabajo nos interesa destacar cómo el movimiento de mujeres, a partir de sus reivindicaciones particulares y luchas amplias, se ha convertido en un factor esencial para el impulso democratizador en la Nicaragua actual.

Para la comprensión del desarrollo y accionar del movimiento, y en particular de las organizaciones que lo conforman, hemos destacado el elemento participación. Comprendemos la participación en un sentido limitado como el involucramiento de sujetos en las diversas acciones e instancias al interior de una organización particular. En un sentido más amplio, como el involucramiento activo y plural de la ciudadanía (como individuos y colectividades) en el control de las instituciones estatales y partidarias, el desarrollo, ejecución y evaluación de las políticas públicas, y en diversas formas de incidencia pública de la sociedad civil. Aunque en este artículo no podemos introducir toda la información (y conclusiones) extraídas del proceso investigativo, consideramos relevante compartir algunos hallazgos en torno al fenómeno participativo y la forma en que éste revela su estado en el movimiento.

Para el análisis de las experiencias dentro del movimiento de mujeres hemos propuesto un modelo de análisis flexible y a la vez preciso. Éste parte de comprender que cada organización posee una cultura de la participación que reúne los referentes que tiene la gente para participar, los conjuntos de ideas, valores y creencias que sobre la participación posee cada colectivo. También que posee ciertas estructuras participativas que se expresan en normas y/o reglas (formales o informales) que dan cuerpo a las diversas modalidades (directa, delegada, activismo, entre otras) de la participación; así como en el conjunto de espacios organizativos más o menos estables -asambleas, coordinaciones, etc.- que abrigan la participación de los integrantes. Por último procuramos registrar aquellas dinámicas de la participación,

2 Utilizamos el término femenino y no feminista por los contenidos e implicaciones específicos (teóricos y politicos) de este último.

3 Para la comandante sandinista Mónica Baltodano el movimiento de mujeres es el único que conserva su autonomía frente a los poderes establecidos (Cuadra Ë Jiménez, 2009, p. 43) 
suerte de componente cronológico del proceso, que expresan el quehacer, el día a día, el conjunto de acciones secuenciadas y temporalmente definibles mediante las que se despliega la participación.

El feminismo ha aportado una crítica a las visiones restringidas de una ciudadanía y democracia liberales que no incluyen una perspectiva de género ni cuestionan las relaciones de poder intrafamiliares. Ha insistido en la necesidad de revisar el impacto político de las categorías convencionales de lo público y lo privado, y el lugar del trabajo domestico en la sociedad. Esta reflexión (y debate) ha marcado las posturas feministas frente a las demandas de participación política, las cuales se concentran en tres ejes fundamentales: a) el énfasis en generar medidas en pro de la paridad, b) la defensa de la autonomía del movimiento, y c) el fortalecimiento de las capacidades de las asociaciones. En el caso de Centroamérica, la lucha por la ampliación de la participación política de las mujeres ha combinado el legado de movimientos insurgentes y revolucionarios, el impacto de los procesos de transición democrática (incompletos y mediatizados por la liberalización económica) y la influencia de los debates y corrientes teóricos globales (Alianza, 2010, pp. 3-4).

\section{Una mirada de contexto: la sociedad civil nicaragüense}

La riqueza de la sociedad civil en Nicaragua se manifiesta en los tipos de organización, los grupos sociales afiliados, las áreas temáticas y los enfoques de trabajo, las relaciones con el estado y la población (Serra, 2007, p. 153).

Existe un acumulado diverso de estudios sobre el fenómeno de la SC en Nicaragua (Serra, 2007, pp. 29-31). Unos son informes de las propias OSC y agencias internacionales (ASDI/BID, 2006) que ofrecen visiones (y evaluaciones) de conjunto del espacio asociativo (Borchgrevink, 2006); otros son ensayos críticos con cierto valor teórico (Núñez, 2004) y algunos son estudios empíricos focalizados (Serra, 2010) que evalúan algún desempeño o proceso particular. Hay textos que ubican la problemática asociativa dentro de los escenarios y dinámicas nacionales (Montenegro, Cuadra \& Saldomando, 2009) y estudios centrados en la relación entre la SC, el Estado y los partidos políticos, con énfasis en las políticas públicas y los espacios de participación que vinculan el accionar de estos actores (Prado, 2009). El tema ha estado atravesado por la polarización política, generando visiones que clasifican a las organizaciones sociales dentro de supuestas intencionalidades y agrupamientos desde una mirada vinculada al oficialismo (Núñez, 2007) que ha provocado respuestas de los aludidos (Wheelock, 2007).

Desde una mirada histórica existe bastante consenso en que durante la historia moderna de Nicaragua la existencia de una auténtica SC quedó limitada por el predominio, en la vida política nacional, de actores conservadores aliados a EEUU (Kinloch, 2008). Durante la dictadura de los Somoza, el estado patrimonialista no sólo controló vastos sectores de la economía y política domesticas (perpetuándose

\footnotetext{
4 Esto demuestra que la afinidad politico partidaria resulta clave para determinar el tipo de relación entre las OSC y los gobiernos de turno (Serra, 2007, p. 148) y que es un fenómeno que se extiende a los intelectuales vinculados a las distintas opciones politicas en pugna.
} 
en una combinación de farsas electorales con oposición leal incluida y represiones sangrientas contra el pueblo) sino que estableció un sistema de control, cooptación y represión hacia los diversos actores civiles y populares. Durante el somocismo se consolidó en el país un modelo de relaciones políticas basado en el patronazgo y el clientelismo, en el que a cambio de empleo, tierras o préstamos, los trabajadores ofrecían su mano de obra y su fidelidad política (Serra, 2007, p. 265).

En la etapa somocista aparece un rasgo repetido en el tiempo dentro de la sociedad y política nicaragüenses: la creación de agentes paraestatales como componente central de una SC oficialista. En la etapa somocista se crearon organizaciones que acosaban a la oposición, denunciaban al campesinado que respaldaba a los guerrilleros y daban aviso a la Guardia Nacional (Silva, 2007). El Frente Sandinista, por su parte, organizó estructuras comunitarias que luego degeneraron en órganos de control: en la insurrección fueron los Comités de Defensa Civil, luego en el poder los Comités de Defensa Sandinista y en la etapa actual parecen reeditarse en los Consejos del Poder Ciudadano (Gertsch, 2010). Durante los años 90 se crearon las Juntas Comunitarias para el Progreso Social (Jcops), que acompañaron los actos y campañas del presidente Alemán (Silva, 2007). Aunque se han señalado (Cruz, 2009) las diferencias entre organizaciones surgidas bajo momentos y móviles históricos diferenciados -los CDS surgen de la población aunque luego se subordinan a los intereses del Estado-partido, los CPC son organizados desde el Estado como mecanismo de participación ciudadana y los Consejos de Liderazgo Sandinista para desarrollar el activismo político- se critica que fenómenos como la pertenencia simultanea a varios espacios (por ejemplo, CLS y CPC) puede generar la utilización de criterios partidistas a la hora de escoger beneficiarios de los bienes y servicios gestionados.

El proceso de fortalecimiento de la SC comienza con la Revolución Sandinista de 1979, donde se produce una expansión de la organización y participación populares (Montenegro, Cuadra \& Saldomando, 2009) pero son el sesgo de un control estatalpartidista y las restricciones a los derechos ciudadanos típicos de un entorno de guerra civil y un modelo clásico de izquierda revolucionaria. Posteriormente llegará el momento de la autonomización efectiva de la SC, que despegará en 1990 con el fin de recursos y tutela del FSLN, lo cual acompañado con la "retirada del estado" y las demandas de asistencia social derivadas de la implantación del modelo neoliberal, conllevará a una gran expansión de las OSC de 1990-1996 (Serra, 2007, pp. 44-49)

El gobierno derechista de Arnoldo Alemán (1997-2002) excluyó a las OSC del Comité de emergencia, lo cual las llevó a crear la Coordinadora Civil, generando presiones sobre los miembros de las OSC y los cooperantes (Serra, 2007, pp. 50-51). La administración de Enrique Bolaños (2002-2006) redujo el acoso a OSC pero mantuvo la pobre cooperación y falta de transparencia en sus políticas al sector, concretando su atención en el CONPES (por vínculos e intereses del presidente) dentro de una continuidad de las políticas neoliberales que llevó a la Coordinadora Civil $(2007,2009)$ a lanzar una campaña de denuncia y protestas contra los acuerdos del gobierno con el FMI.

Para el estudio de la SC diversos analistas consideran importante destacar la vinculación existente entre sus organizaciones y los procesos (y modelos) de participación (Prado, 2010; 2009) toda vez que desde éstos se busque canalizar 
demandas sociales y presionar por formas de redistribución del poder desde las organizaciones sociales (Montenegro, Cuadra \& Saldomando, 2009, p. 52). A partir de los aportes de estos enfoques podemos adelantar una periodización del fenómeno en las diferentes fases de la Nicaragua postsandinista:

(1990-1994) - Caracterizada por las presiones de las organizaciones revolucionarias (campesinas, obreras, estudiantiles) en resistencia al emergente modelo neoliberal; entorno de crisis sociopolítica con poca institucionalización de la participación y concertación. Expansión de las ONG (muchas con personal sandinista) y sus nexos con la Cooperación Internacional.

(1995-1999) - Reducción de la protesta social -con aceptación del rumbo económico y anclaje en la gestión/concertación local-gracias al freno ejercido desde los partidos y el Estado. Creación formal del CONPES, expresión de la demanda histórica por un espacio nacional de concertación para el diálogo Estado-SC 5 , aunque se trata de una instancia que nace limitada por su carácter consultivo, su dependencia presidencial y la escasez de recursos.

(1999-2006) - Expansión de los espacios de concertación y participación, y creación de legislación afín a la Ley 475 (2003) que incluye a las asociaciones civiles -previo reconocimiento de consejo municipal- como actores en políticas públicas locales. ${ }^{6}$ No obstante, se fomenta una participación funcional (de impronta neoliberal) que restringe las alternativas a atender políticas inmediatas y locales -sin tocar los problemas nacionales- y desresponsabiliza al Estado transfierendo a la sociedad la respuesta a los graves problemas sociales (ver Montenegro, Cuadra \& Saldomando, 2009, pp. 117-122).

(2007-actualidad) - Los modelos de participación están inmersos en la crisis política que divide al país. Se contrapone un modelo de acompañamiento pluralista concertacionista (CDM) frente a otro de acompañamiento partidista y paragubernamental ${ }^{7}$, donde el Ejecutivo recibe y resuelve demandas y las organizaciones -aunque formalmente deben orientar y corregir la acción del primerocarecen de canales para un diálogo horizontal simétrico y de mecanismos de control sobre éste (Montenegro, Cuadra \& Saldomando, 2009, pp. 52-55). Se reproduce un "autismo organizativo" con un FSLN que sólo reconoce sus organizaciones y espacios de participación y un "autismo elitista" donde la derecha privilegia sus grupos sociales y cotos de poder (Montenegro, Cuadra \& Saldomando, 2009, p. 109).

Sin embargo, en los espacios y plataformas del FSLN y el Partido Liberal Constitucionalista (y sus caudillos tradicionales) existe un plural campo de activismo y reflexión sociales, donde encontramos aquellas OSC comprometidas con una salida democrática, antineoliberal y antiautoritaria a la problemática nacional. Como se ha señalado "(...) la base social progresista del país se ha escindido y una buena parte de

\footnotetext{
5 Por el recelo de los políticos del gobierno y la oposición a compartir su poder dicha instancia no será operativa hasta 1999. Para 2006 estará integrada por 179 miembros procedentes de sindicatos, OSC, gobiernos locales, universidades, movimientos sociales, entre otros (Serra, 2007, p. 130).

6 En los espacios locales las OSC y los gobiernos locales han compartido posturas respecto, por ejemplo, a políticas y distribución de presupuestos del gobierno central (Serra, 2007, p. 157)

7 En otros textos se diferencian tres modelos: el del Sistema de Participación Ciudadana, el modelo del FSLN (CPC-GPC) y el diverso de las OSC. Ver Montenegro, Cuadra y Saldomando (2009, p. 127).
} 
ella, mayoritaria quizás, a estas alturas está afuera del control del aparato frentista, incluyendo a sectores dentro de las mismas organizaciones de filiación sandinista" (Montenegro, Cuadra \& Saldomando, 2009, p. 166). Es en estos espacios donde podemos hallar aquellas fuerzas que expresan el potencial auto organizativo de la SC en un estado de mayor madurez y donde hallamos las propuestas más congruentes con una auténtica democracia participativa.

Ello no quiere decir -como algunos de sus miembros se autorepresentan y la retórica opuesta reafirma- que en las OSC y movimientos que afirman la autonomía y la autogestión de cara a las lógicas del Estado y el mercado, se agote la SC realmente existente puesto que ésta, como hecho sociológico, reúne también organizaciones vinculadas (estructural y culturalmente) a los actores dominantes: partidos, empresarios e iglesias. ${ }^{8}$ Ese es el caso de la Coordinadora Social, vinculada al FSLN, que reúne a organizaciones como el Frente Nacional de los Trabajadores (FNT), la Central Sandinista de Trabajadores (CST), la Asociación Nacional de Educadores de Nicaragua (ANDEN), y la Federación de Trabajadores de la Salud (Fetsalud).

Las críticas al fenómeno de la SC en Nicaragua provienen de dos matrices fundamentales que conviene diferenciar. Una proviene de los ataques vertidos por el oficialismo y combina la hipocresía (pues varios de los críticos oficialistas sobrevivieron durante los años 90 gracias a la creación de ONG y consultorías aprovechando contactos forjados en su etapa de funcionarios Sandinistas) con la perversidad, pues al denunciar los reales peligros de elitización de un sector de las OSC ocultan que -bajo su retórica de democracia participativa y Pueblo Presidentese oculta un viejo modelo de participación movilizativa y vertical dirigido por una jefatura política ex revolucionaria capaz de armonizar con la elite tecnocrática y empresarial del neoliberalismo.

Por otro lado, existen críticas que toman nota de la repetición dentro de la SC nicaragüense de tendencias afines a las internacionales. La oenegizacion del campo (paulatina sustitución del activismo por la profesionalización) que impide la necesaria complementariedad de roles, la preeminencia de las ONG por sobre los movimientos comunitarios, el impacto de la lógica tecnocrática sobre las experiencias autogestionarias y la aparición de una suerte de "élite (cultural y socioeconómica) de la sociedad civil y la cooperación" son algunos de esos fenómenos (ver Borchgrevink, 2006; Chahim \& Prakash, 2010; Stenber, 2010).

Al ser el CONPES un organismo consultivo del Ejecutivo con amplia participación de la SC, Ortega buscó modificar su composición y directiva para asegurar una mayoría para los CPC y organizaciones afines a su partido, y nombró a su esposa la señora Murillo como Secretaria Ejecutiva del mismo CONPES (Chamorro, 2009). Ello provocó el rechazo de las organizaciones agrupadas en la Coordinadora Civil y en la Red de Desarrollo Local, lo que fue replicado por el presidente en el discurso del 1ro de mayo de 2007, cuando sentenció “...que le den chance ahora a los pobres, a los trabajadores (...) invitaremos también a esos grupos que se autodenominan Sociedad Civil, que son financiados por los emisarios 
del imperio (...) estamos dispuestos a debatir en el CONPES todas estas políticas económicas, así como los acuerdos con el Fondo Monetario Internacional" (Radio La Primerísima, 2007). El tono de este discurso fue amplificado en el acto del 19 de julio, día de la victoria de la Revolución Sandinista, siendo una señal de los conflictos que se generarían a partir de ese momento entre el gobierno y sectores de la ciudadanía organizada y continuarían, con altibajos, hasta el presente.

En la política nicaragüense el lugar de la mujer -si bien el más consolidado de Centroamérica- ofrece un cuadro variopinto y refleja las amenazas de los giros conservadores de las pasadas dos décadas. La carencia de una legislación específica orientada a la ocupación de puestos en partidos o instituciones públicas (pese a que el FSLN y el PLC sí contemplan cuotas en sus estatutos) y la persistencia de factores "extrapolíticos" que afectan el desempeño de las mujeres (como la penalización del aborto y la creciente feminización de la pobreza) han lastrado su participación política en la sociedad nicaragüense.

Dentro de los partidos, el MRS ha sido la fuerza más coherente en la defensa de los derechos de la mujer, contando con más de una diputada en su bancada, superando porcentualmente al resto de las formaciones políticas (Alianza, 2010, pp. 27-30). Pese a ello, el partido no ha fijado estatutariamente una cuota para sus mujeres militantes, previendo ante la situación de acoso a que se ha visto sometido, la posibilidad de defenderse de sanciones en caso de no poder cubrir dicho requerimiento en determinado momento (Alianza, 2010, p. 68).

Por su parte, el FSLN ha manejado la retórica de un 50\% de poder para las mujeres, ejemplificándolo con el poder que ostenta la primera dama, Rosario Murillo, aunque no existen evidencias de que esta situación se replique a otros niveles locales y espacios institucionales. Donde ha habido cierto avance bajo el actual gobierno ha sido en la presencia femenina en cargos de dirección ministerial, ascendiendo en 2008 a 38\%, frente a un 25\% en la administración anterior (Bolaños), 10\% en la época revolucionaria y similar cantidad en el periodo somocista (Alianza, 2010, p. 28).

\section{El movimiento de mujeres en Nicaragua: un actor relevante}

La historia del movimiento de mujeres abarca varios momentos atendiendo al carácter de la lucha de las féminas: Sufragistas -de mediados del siglo XX a los años 70-, Compañeras de la Revolución -de los años 70 a 1990-, Autónomas -de 1990 hasta hoy (Cuadra \& Jiménez, 2009, p. 11). Pero sin duda, es con la Revolución Sandinista que emerge, como saldo inesperado, el que hoy es el movimiento feminista más importante de Centroamérica (Kampwirth, 2009, p. 83) a partir de una cantera femenil que abarcaba, en las décadas del 60 y 70, a cerca de un 30\% del total de luchadores antisomocistas (Alianza, 2010, p. 4).

En la legislación y las políticas el proceso revolucionario expandió los derechos de las mujer en el ámbito familiar y laboral (Chinchilla, 1994) a partir de su incorporación a la defensa y producción (Cuadra \& Jiménez, 2009, p. 12), aunque pronto se generaron conflictos entre las "identidades oficiales" de la mujer 
revolucionaria y aquellas emergentes. Una protagonista recuerda que "la revolución tenía una idea de mujeres obreras, campesinas y pobladoras, pero la mayoría de las mujeres organizadas no entraba en esas categorías...en plena Revolución se crea el Partido de la Izquierda Erótica (con Gioconda Belli, Sofía Montenegro y Alba Palacio en sus filas) lo que trajo un conflicto con el FSLN [...] a partir de los ecos de un encuentro feminista en Tasco (México) se impulsó la necesidad de una representación de las mujeres en las estructuras y la política sandinista, por lo que se plantea a Bayardo Arce, de la dirección del Frente, la necesidad de mayor autonomía; él propone posponer ese análisis y cambio para después de las elecciones de 1990..." (A. Solís, entrevista, 21 de octubre de 2010). ${ }^{9}$

Dentro del proceso revolucionario van emergiendo actores y visiones del movimiento, que en cierto modo sobreviven hasta hoy (Chinchilla, 1994). En 1979 surge la Asociación de Mujeres Nicaragüenses Luisa Amanda Espinoza (AMNLAE), estrechamente vinculada al FLSN -hasta el día de hoy-, que pronto fue acompañada por el Comité de Madres de Héroes y Mártires, organización portadora de la visión clásica de la "madre sufrida y revolucionaria". A mediados de los 80 aparecen unas secretarías de mujeres en las estructuras sindicales más beligerantes e independientes y se produce el reconocimiento de derechos femeninos en la Constitución (1987). Para fines de la década surgen las primeras organizaciones de mujeres de sesgo autónomo, integradas por militantes desencantadas con la ejecución del FSLN pero que se consideraban revolucionarias ${ }^{10}$ (Kampwirth, 2009, pp. 85-86).

En 1990 se produce la primera gran ruptura de mujeres con AMNLAE, que se coronó en marzo del siguiente año con la primera movilización autónoma de mujeres conocida como la Feria del $52 \%{ }^{11}$. Dicho foro representó la declaración de independencia del movimiento feminista, emergiendo ocho redes conformadas por unos 250 colectivos, la mayoría de los cuales rechazó formas de coordinación estructuradas frente a una importante minoría que abogaba por más centralización ${ }^{12}$ (Kampwirth, 2009, pp.90-91).

En febrero de 1992 el novel Movimiento Autónomo de Mujeres ${ }^{13}$ convoca al Primer Encuentro de Mujeres Unidas en Diversidad, reuniendo unas 800

9 "Se cuestionó el diseño y ejecución de una Reforma Agraria dirigida hacia los hombres que expulsaban a sus esposa cuando agarraban tierra y dinero y se buscaban mujeres jóvenes..." (A. Solís, entrevista, 21 de octubre de 2010).

10Una testimoniante recuerda "...hubo una primera generación vinculada al FSLN (la de Sofía Montenegro) que fueron separadas del partido por divisionistas y por no impulsar prioritariamente la agenda de los pobres... allí surge una tensión histórica de origen entre el feminismo y el FSLN... yo formé parte de la generación intermedia del feminismo hace 25 años, donde comencé aprendiendo de las primeras, recreando formas de organización, pasando de una luna de miel a etapas de tensiones y separaciones" (M. M. Blandón, entrevista, 20 de octubre de 2010).

11 El término aludia al porcentaje ocupado entonces por las féminas dentro del total de la población nicaragüense.

12 "Existió un debate dentro del movimiento de mujeres donde personas como Sofía Montenegro abogaban por un movimiento nacional, capaz de centralizar fuerzas y politizarlas, con un liderazgo único... y otras abogaron por redes, articuladas por temas y ritmos diversos, rechazando la organización centralizada heredada del FSLN y la emergencia de un nuevo vanguardismo, esta vez dentro del movimiento feminista.. Esta última postura prevalece, lo cual es valorado por Sofía como "años perdidos" (G. Gómez, entrevista, 23 de octubre de 2010).

13 Una testigo de esos tiempos recuerda que "El MAM surge con algunas compañeras de corazón rojinegro, pero con diversidad de posturas teóricas y en torno a la autonomí... cobra fuerza la idea de rechazar ser parte del partido, su ala femenina... en el quinquenio 1990-1995 se da un conflicto entre las mujeres populares y las ideólogas, un conflicto de liderazgos donde el MAM rechaza su conexión con el FSLN y las AMNLAE la mantienen" (M. M. Blandón, entrevista, 20 de octubre de 2010). Sin embargo, una dirigente del MAM enfatiza: "Se crean artificialmente confrontaciones entre intelectuales y activistas, en el MAM tenemos tanto sectores populares (campesinas de Jalapa) como medios" (A. Solis, entrevista, 21 de octubre de 2010). 
participantes en el marco de una búsqueda colectiva de identidad y autonomía de las mujeres organizadas respecto al Estado y los partidos (Cuadra \& Jiménez, 2009, pp. 13-14). En el cónclave continúa el debate sobre las formas idóneas de organización (redes, ONG o movimientos) ${ }^{14}$ conformándose redes temáticas (por ejemplo, Red de Mujeres contra la Violencia) que serán seguidas por redes territoriales (por ejemplo, Red de Mujeres de Matagalpa, conformada en septiembre), concebidas como un espacio de apoyo mutuo, construcción y coordinación colectiva (Grupo Venancia, 2002, pp. 27-28). Cobra fuerza la creación de ONG (producto de la búsqueda de recursos y de las exigencias de formalización gubernamental) y los vínculos con una cooperación internacional que expande su accionar, lo que es aprovechado por las mujeres organizadas ${ }^{15}$ (Grupo Venancia, 2002).

\section{Disensos y conflictos}

A partir de 1998 y hasta 2006 se asistió a un proceso de consolidación y rupturas ${ }^{16}$ dentro del movimiento, que adquirió mayor visibilidad y beligerancia a partir del caso de Zoliamérica Narváez (1997), la respuesta (auto)organizada al impacto del huracán Mitch (1998) , la oposición a los sucesivos pactos (2000 y 2005) dentro de las élites políticas (acuerdos Ortega-Alemán-Bolaños-Obando) y el proceso de penalización del aborto terapéutico, consumado en 2007 con apoyo del FSLN.

Las posibilidades de concertación entre organizaciones de mujeres de diferente filiación ideológica han sido repetidamente saboteadas por la polarización política y por la incidencia directa de los liderazgos y partidos dominantes. En 1995 un intento de conformar una Coalición Nacional de Mujeres plural (integrada por sandinistas, liberales y sin partido) para avanzar en la conformación de una agenda consensuada de políticas públicas fue directamente saboteada por Arnoldo Alemán quien, con el apoyo de jerarquías eclesiásticas, la acusó de ser "una coalición de extranjeros y feministas" enarbolando espantajos de la soberanía nacional y la moral social (Kampwirth, 2009, pp. 93-95).

En el bienio 2005-2006, en pleno proceso de "refundación” del MAM, se produce una crisis que profundiza los disensos dentro del movimiento de mujeres a partir de la decisión de lideresas de establecer una alianza formal con el partido Movimiento Renovador Sandinista (MRS). Lo que era presentado como una muestra de autonomía y madurez -según las dirigentes del MAM- expresaba una

\footnotetext{
14"En 1992, ante una ruptura con el FSLN, se dan dos visiones: la de crear un movimiento unido, defendida por la Corriente Nacional Feminista, y la de crear redes, con influencia de mujeres de origen estadounidense que vivian en Nicaragua, de donde nace y sobrevive la Red de Mujeres contra la Violencia" (A. Solís, entrevista, 21 de octubre de 2010).

15 En el lado nocivo del fenómeno, el impacto de los vínculos con la Cooperación (que frecuentemente exigió criterios de "unidad y homogeneidad" a un movimiento diverso) generó el auge de la contractualización de los nexos entre las OSC, el cortoplacismo vinculado a la "gestión de proyectos", la institucionalización excesiva de las agendas y la precariedad de los colectivos pequeños y rurales frente a otros grandes de anclaje urbano (Cuadra Ë Jiménez, 2009, pp. 58-59).

16 "En los 90 se da una primera ruptura en el Comité Nacional Feminista, grupo que gestaba recursos y elaboraba la teoria, pereciendo la posibilidad de aglutinar diversas expresiones... En el 2000 se da un nuevo intento de reunir una diáspora dispersa, en la segunda versión del Comité, generándose una discusión autocrítica y una nueva luna de miel... pero se mantienen las tensiones por los estilos de liderazgo y las militancias partidarias (en esta ocasión vinculadas al MRS) y las principales lideresas oscilan entre la cercanía a dicho partido y la autonomía" (M. M. Blandón, entrevista, 20 de octubre de 2010).
} 
amenaza dentro de la lógica de grupos opuestos a la medida (Cuadra \& Jiménez, 2009, p. 54).

Una dirigente del MAM recuerda que "en un análisis que realizamos en abril de 2006, el peor escenario que vimos era el triunfo de una fuerza autoritaria, fundamentalista y neoliberal, capaz de pasar por izquierda, como el FSLN... el mejor escenario sería el arribo de fuerzas democráticas (de izquierda y derecha) que abrieran el espacio político, como el MRS" razón por la cual "vimos que existía una necesidad de alianza, ya que por el pacto (2000) y las reformas constitucionales (2004), el MAM se metió de lleno en conflicto en el espacio político, combatiendo simultáneamente al PLC y al FSLN, y vimos la necesidad de converger con fuerzas nuevas. Entonces escogimos al MRS, ya que la ALN era democrática pero neoliberal" (A. Solís, entrevista, 21 de octubre de 2010) ${ }^{17}$. Esta dirigente recuerda que "ante el acuerdo con el MRS hubo cuestionamiento de grupos de mujeres por supuestas amenazas a la autonomía; pero nosotros defendimos que era un acuerdo entre iguales y no incondicional, en base a cinco puntos que ellos se comprometían a cumplir...". Sin embargo, otra participante lo recuerda así: "En 2006 se diseña un plan para participar en la política cuando una facción del MAM decide, sin consultar al resto, endosar un compromiso de alianza del MAM con el MRS... pese a apoyo de la mayoría que simpatizaba con el MRS no queríamos adscribir el movimiento a partido alguno... decidimos que las lideresas que corrían en postulaciones o campañas tenían derecho a hacerlo como personas, pero sin el membrete del MAM (donde habían MRsistas, liberales, orteguistas y sin partido)... la respuesta de estas ocho o nueve lideresas fue expulsarnos con una carta acusatoria de "hacer el juego a Ortega" y ofensas personales como bicheras" (M. M. Blandón, entrevista, 20 de octubre de 2010) ${ }^{18}$. Otra protagonista testimonia: "La alianza MAM MRS fue necesaria pero se violentaron los tiempos y procesos de toma de decisión, los mismos que nosotras habíamos consensuado, hubo choques de liderazgos y protagonismos... la expulsión de compañeras fue algo penoso que yo apoyé y es de las cosas que me arrepiento de haber hecho..." (G. Gómez, entrevista, 23 de octubre de 2010).

A partir de esa coyuntura, los conflictos en el movimiento de mujeres (y dentro de su segmento más beligerante y autónomo) que definieron con mayor claridad la existencia de grupos y/o redes más o menos demarcados entre si ${ }^{19}$, se suman a las dificultades persistentes para articular agendas con las organizaciones afines al FSLN. La actitud de AMNLAE es ilustrativa de la oscilación entre la lealtad partidista y la defensa de la identidad e intereses femeninos. Recuerda una feminista que "cuando el caso de Zoilamérica, AMNLAE no respaldó la condena a Ortega y se mantuvo al margen, aunque sin subordinarse completamente al FSLN... pero ello va cambiando

\footnotetext{
17 "Nosotras reconocemos la necesidad de dos variables para avanzar los derechos de las mujeres: un movimiento autónomo y un gobierno progresista... pero éstas nunca han coincidido en nuestra historia” (A. Solís, entrevista, 21 de octubre de 2010).

18 "Ello generó la ruptura de amistades, significo un duelo, la pérdida de un grupo de pertenencia, donde militar y aportar... al ser expulsadas ocho compañeras con liderazgo y nuestros respectivos grupos creamos el Foro Sexualidad, Maternidad y Derecho... en ese grupo se generó un ulterior conflicto por liderazgos y nuevamente se genera una crisis y expulsada de este espacio" (M. M. Blandón, entrevista, 20 de octubre de 2010).

19 Es en esa coyuntura de ruptura con el MAM donde emerge el Movimiento Feminista (Cuadra Ë Jiménez, 2009, pp. 24-25) con un formato algo más flexible y menos jerarquizado, con una membresía que combina mujeres y colectivos, y conformado por 14 organizaciones que en ocasiones tienen capítulos locales. Ver www. movimientofeministanicaragua.org
} 
en los últimos años... hasta 2007 AMNLAE tuvo mejores relaciones con el MAM, hicimos acciones conjuntas por nuestros derechos, incluso introdujo el recurso de inconstitucionalidad del MAM por la penalización del aborto terapéutico... después nos hemos confrontado, pero sí con otras mujeres cercanas al frente" (A. Solís, entrevista, 21 de octubre de 2010). Otra activista destaca: "Hay una suerte de esquizofrenia en las mujeres del FSLN que rechazan la penalización del aborto apoyada por su partido y días después fueron fiscales de mesa disciplinadas que le apoyaron en medio del fraude" (G. Gómez, entrevista, 23 de octubre de 2010).

En una suerte de balance crítico, una feminista señala: "El campo feminista hoy tiene tres grandes actores: uno es el MAM, fracturado y con hegemonía de Sofía o Azahálea, con una cultura política cuyos discursos son democráticos pero donde la infidelidad a las lideresas define la expulsión; otro es la Red de Mujeres contra la Violencia, que es una suerte de tierra de nadie, una coalición que cuenta con centros para ofrecer servicios a mujeres y posee un trabajo de base destacado pero tiene liderazgos débiles, dentro de ésta se realiza un trabajo sucio detrás de los procesos y rotaciones de cuadros infiltrados tanto por el MAM como por el Movimiento Feminista... el tercero es el Movimiento Feminista, también fracturado, con figuras destacadas... en los tres espacios se combinan un trabajo de calidad con prácticas políticas traídas de la clandestinidad y de la Seguridad del Estado” (M. M. Blandón, entrevista, 20 de octubre de 2010).

Subsisten intentos de concertar acciones y posturas en ciertos temas en aras del interés común. Una activista señala: "Desde 2006 trabajo en espacio institucional (IPAS $)^{20}$ con el aborto como centro de acción... con nuestra fuerza y adversarios la penalización del aborto no podía ser detenida pero hemos creado un Grupo Multidisciplinario donde hemos compartido información y establecido nexos con sandinistas y opositores, organizaciones de mujeres y autoridades del MINSA; sociedades medicas, centros de DDHH, religiosas, etc... hemos apostado por dedicar energías donde sea productivo, sin peleas, culpas o maltratos a nadie... en el Grupo no hemos tenido bajas y mantenemos las reglas del juego, con altibajos de recursos y trabajo... hemos repartido las tareas como una orquesta, sin bajar línea, aprendiendo con el ejemplo del trabajo de las mujeres religiosas de base" (M. M. Blandón, entrevista, 20 de octubre de 2010)21.

\section{La participación y la democracia en el movimiento}

La participación dentro del movimiento (y sus organizaciones) está íntimamente relacionada con sus formatos organizativos y estrategias de lucha, articulados alrededor del ejercicio de una ciudadanía plena (incidencia en foros de concertación, creación de leyes, marchas de calle, etc.) y la defensa de derechos e integridad de mujeres (Cuadra \& Jiménez, 2009, p. 31). Existe consenso sobre la emergencia "sobre la

\footnotetext{
20 Ver http://www.ipas.org/Publications/Ipas_en_Centroamerica.aspx

21 En otra muestra de las latentes contradicciones internas del movimiento y del socorrido uso de la autoridad (iautoritarismo?) como recurso para el orden, la testimoniante revela "En este espacio otro grupo de feministas intentaron tomar el poder, descalificando la lucha por el aborto terapéutico (lo posible en coyuntura actual) y reclamando el aborto total y pretendieron bajar línea... aquí comencé a ejercer un liderazgo fuerte para frenarles y hacer respetar la democracia...” (M. M. Blandón, entrevista, 20 de octubre de 2010).
} 
marcha” de las estructuras de participación, sin nacer éste de una reflexión previa de corte teórico (Cuadra \& Jiménez, 2009, p. 60). Hemos constatado que, aunque la personería jurídica y los nexos con la Cooperación favorecen el establecimiento de estructuras permanentes, con división de trabajo y jerarquías internas, hay un discurso crítico respecto a los potenciales y límites de la identidad $O \mathrm{NG}^{21}$.

Como forma de fortalecer sus estructuras y expandir su presencia territorial, actores sociales relevantes como el Movimiento Feminista, el MAM y la Red de Mujeres contra la Violencia han creado capítulos locales privilegiando las zonas rurales (Cuadra \& Jiménez, 2009, p. 44). En el caso del MAM, su estructura combina la adscripción individual con el establecimiento de una asamblea amplia y capítulos locales regidos por una Coordinación nacional ${ }^{22}$. Una dirigente describe así la estructura interna: "El MAM está compuesto por una Coordinadora Política y dentro de ésta una Comisión Ejecutiva que conformamos varias compañeras (Juana, Sofía y Azahálea)... también tenemos una Asamblea con unas 60 integrantes que debe reunirse cada dos meses, pero no siempre ocurre... y hay expresiones territoriales cuando hay más de una persona en cada localidad" (A. Solís, entrevista, 21 de octubre de 2010).

Las coyunturas políticas nacionales y las dinámicas internas se combinan para fortalecer el liderazgo tradicional de las fundadoras en detrimento de una participación y democracia más abiertas. Se señala que "en 2008 el trabajo de organización (de funcionamiento interno, eleccionario, de ética) fue suspendido por el acoso del gobierno, pero este año (2010) hemos retomado la discusión y tenemos pendiente la Asamblea General” destacando los peligros de la personalización del poder cuando expresa: "tememos que los procesos eleccionarios se conviertan en una competencia, creemos que la Coordinación Política ha estado a la altura de las circunstancias, ya que no es sólo tener personas electas... realmente hay un problema en Managua -donde se solapan la dirección nacional y local- y en los departamentos donde tenemos que definir quien asume lo nacional" (A. Solís, entrevista, 21 de octubre de 2010) ${ }^{23}$.

En general se reconoce la susbsistencia dentro del movimiento de una visión unificadora, que es por un lado depositaria del legado de la cultura jerárquica y verticalista del FSLN y por otro, considerada la mejor forma de enfrentarse a un partido disciplinado como aquel. Sin embargo, el que exista un pensamiento que coarta el debate y el disenso, y que se generen conflictos por la filiación partidaria de las organizaciones, sin duda cuestiona la calidad de la representación dentro del movimiento (Cuadra \& Jiménez, 2009, pp. 62-65).

El activismo social (y por ende político) del movimiento de mujeres les ha

21Si para Sofía Montenegro las ONG son instituciones aliadas del movimiento y Marta María Blandón las valora como un mecanismo para obtener recursos que permiten promover derechos pero no formas abiertas de participación (Cuadra $\mathcal{E}$ Jiménez, 2009, pp. 61) otra destacada lideresa la entiende como "suerte de empresas sociales, no como movimientos" (A. Solis, entrevista, 21 de octubre de 2010).

22 "Cuando en 2005 refundamos el MAM propusimos una organización mixta individual-organizativa... hoy lo formamos personas que hacemos parte de otras organizaciones de mujeres, de defensa de derechos, etc. e integramos el MAM por decisión propia antes que por representación funcional de organización alguna" (A. Solis, entrevista, 21 de octubre de 2010).

23Ante la pregunta sobre la deseabilidad de una rotación de la dirección del MAM, la respuesta fue más bien imprecisa y elusiva "están funcionando los enlaces con los territorios, hay un reto de descentralización y articulación, sin romper la unidad y la lógica del movimiento” (A. Solis, entrevista, 21 de octubre de 2010). 
llevado a agudas confrontaciones con el Estado, especialmente en las administraciones del caudillo liberal Arnoldo alemán y el comandante Daniel Ortega. En esta última (en septiembre y octubre de 2008) se generó un grave conflicto por la acusación a diferentes ONG (entre éstas, dos de mujeres: el MAM y el Grupo Venancia) de realizar lavados de dinero y campañas de promoción del recién ilegalizado aborto. Esto conllevó el allanamiento de las oficinas del MAM y la incautación de documentos de la organización, a la vez que se promovía (con poco éxito) la creación de una suerte de "contramovimiento" filosandinista denominado "Blanca Arauz" (Cuadra \& Jiménez, 2009, pp. 29-30). En Matagalpa, las mujeres organizadas en el Grupo Venancia también resintieron la arremetida ${ }^{24}$.

Semejante acoso combinado de los poderes del Estado, el partido oficial y sus organizaciones/grupos de choque afines, dirigidos contra medios de comunicación críticos y organizaciones feministas, tenía el propósito de enviar señales claras a toda la SC y cooperación de las intenciones gubernamentales de no tolerar desafíos a sus intentos de establecer una hegemonía política nacional. La estrategia atravesó por varias fases: 1) copar espacios existentes y poner personas afines (evidenciado por la imposición del dirigente sandinista Gustavo Porras en el CONPES), 2) ejemplarizar rebeldes (como las acciones contra CINCO y MAM), 3) controlar los recursos de la cooperación y asustarla (imposición de Manual de Procedimientos Administrativos de Organizaciones Internacionales y Nacionales para condicionar el apoyo únicamente a $\mathrm{ONG}$ con personería jurídica y negar recursos a campañas o acciones de incidencia política) (Montenegro, Cuadra \& Saldomando, 2009).

Sin embargo, la sostenida (y desigual) lucha en defensa de sus posiciones de cara al gobierno no ha disminuido la criticidad de algunas militantes del movimiento sobre las estrategias elegidas por sus compañeras. Ante el apoyo dado por el MRS (y por organizaciones aliadas como el MAM) a la candidatura del líder conservador Fabio Gadea como supuesto candidato unitario de la oposición para las elecciones presidenciales de 2011, una activista señaló "El antidanielismo nos ha nublado la vista, no se puede apoyar a Fabio, hoy no sabemos adónde va el MAM apoyando a un líder conservador que, por sus ideas, quiere retroceder Nicaragua al siglo XIX... en las Venancias no apoyamos esa alianza con Gadea y nos preocupa a dónde va, porque lo que necesitamos es una izquierda crítica, diferente (G. Gómez, entrevista, 23 de octubre de 2010). En idéntica postura otra feminista expresó: "Cuando veo a Víctor Hugo Tinoco, por quien voté, hacer campaña por Fabio Gadea, me arrepiento” (F. Enríquez, entrevista, 23 de octubre de 2010). En ese sentido es notorio el reclamo de constitución de un movimiento social que lleve la política más allá de los espacios gubernamentales. Como decía una feminista: "Aquí no se entiende hacer campaña para otra cosa que no tener lugar en el gobierno... esa lógica está moviendo al MRS, no se cree ni siquiera en hacer presión desde el parlamento, por ejemplo" (L. Pérez,

\footnotetext{
24 Con amargura y sin ocultar su corazón rojinegro las Venancias recuerdan: "el acoso de 2008 nos dolió mucho viniendo del FSLN, pues dediqué mi vida a la Revolución y no puedo guardar rencor" (F. Enriquez, entrevista, 23 de octubre de 2010). "La orden de allanamiento contra las Venancias fue directo al corazón... ni Alemán nos trató así... decían que las ONG éramos ladronas de la cooperación, que era ilegal organizarse sin aval legal... quitaban el tema de incidencia politica del trabajo de las ONG porque sólo les querían permitir hacer labor social... eso fue una campaña de la Ministra de Gobernación" (L. Pérez, entrevista, 23 de octubre de 2010).
} 
entrevista, 23 de octubre de 2010).

Sin embargo, dentro del movimiento de mujeres podemos encontrar colectivos y personas cuyo accionar, si bien está imbricado con las grandes luchas nacionales, adquiere una peculiar relevancia cuando se conoce el proceso de génesis y desarrollo de su organización y accionar dentro de espacios locales. Ese es el caso del Grupo Venancia, emblemático en la ciudad de Matagalpa, cuya experiencia abordaremos a continuación en apretada síntesis, tratando de conjugar lo histórico con el presente.

\section{Las Venancias: una historia de persistencia y creatividad}

Llevamos dos décadas viendo cómo gobiernos neoliberales, con políticas que han venido deteriorando el nivel de vida sobre todo de los sectores empobrecidos, se autoproclamaban gobiernos democráticos. Hoy tenemos un gobierno que en nombre de la justicia social viola nuestro derechos civiles y políticos (Grupo Venancia, 2009, p. 25).

El Grupo Venancia es un colectivo autónomo de feministas que posee su sede en la ciudad de Matagalpa pero destaca por su sostenido activismo en escenarios locales y nacionales, así como por su participación en diversos foros e iniciativas internacionales. Se definen como organización de Educación y Comunicación Popular Feminista implicada en la construcción del movimiento de mujeres (Grupo Venancia, 2002) y hereda su nombre de una líder campesina antisomocista de la región durante los años 60. La idea de desarrollar sus discursos y acciones desde una Educación y Comunicación Popular feministas apunta a varios ejes: a) decodificar identidades tradicionales de género (desde lo psicológico y cultural) y socializar visiones alternativas a partir de la generación de materiales y campañas de comunicación, b) comprender la organización como un espacio de desarrollo colectivo, y c) rechazar los fenómenos de elitización y las tendencias a presentarse como "expertas" o "perfeccionadas" por feminismo, manteniendo un vínculo orgánico con la comunidad y otras organizaciones y grupos no formalizados de mujeres de extracción popular (Taller, 23 de octubre de 2010).

En 1991 se produce la creación del Grupo a partir de la iniciativa de dos activistas extranjeras (Helen y Yeta) vinculadas a tareas de alfabetización y comunicación popular ${ }^{25}$. Desde los inicios hace una apuesta por la autogestión y la solidaridad como valores de su cultura de participación pues los primeros recursos para su activismo provienen de pequeñas donaciones, al mismo tiempo que surge la idea de mantener una igualdad de salarios entre todos los miembros como parte de una vocación democrática ${ }^{26}$. Es testimonio compartido por "las Venancias" que en el Grupo no se trabaja (pese a la carencia de recursos) persiguiendo la aprobación de proyectos, por lo que se promueve la generación de "estrategias y fondos propios" para preservar "la autonomía" al punto que se han "cortado relaciones" con la cooperación cuando se precie injerencia (Grupo Venancia, 2002).

25La salida de las fundadoras de la organización para dedicarse a otras tareas generó un duelo colectivo que "las Venancias" procesaron creando un espacio de crecimiento personal para el manejo de las relaciones interpersonales y la autoreflexión (Grupo Venancia, 2002, p. 32).

26 "El Grupo Venancia intentó funcionar como una cooperativa donde la guardiana y la directora ganaban lo mismo, y con una apuesta ideológica por la igualdad... asi funcionaron hasta el 2000 y pico..." (V. Delgado, entrevista, 25 de octubre de 2010). 
Para 1992 el Grupo obtiene los primeros financiamientos de parte de ONG extranjeras, por lo que comienzan a realizar una planificación estratégica creando varias líneas de trabajo (capacitación, organización y cultura) e imprimiendo sus primeros materiales de trabajo y difusión. Como parte de su proceso de fortalecimiento y desarrollo organizativo, en 1993 obtienen su personería jurídica, lo que amplifica su acceso a las ONG y la cooperación internacional, conformando una primera junta directiva del Grupo que incluye a todos sus miembros.

\subsection{Las estructuras y dinámicas de participación}

A partir de la experiencia de dicha junta directiva en el Grupo se constituye un espacio participativo y de debate (Grupo Venancia, 2002, p.21) como eje del colectivo, donde todas comienzan a planificar, evaluar y decidir. Al tiempo se va estableciendo un periodo de integración para nuevos miembros, identificándolos, orientándolos en su incorporación al trabajo y cuidando la calidad de los procesos internos. Todo el tiempo en los documentos y testimonios de las integrantes se destaca la importancia de simultanear la participación individual y representación colectiva en los diferentes espacios del movimiento feminista (Taller, 23 de octubre de 2010) y de evitar tanto el oenegismo como el activismo sin profundización de pensamiento ni articulación con otras organizaciones (Grupo Venancia, 2002, p. 15).

La cultura y estructuras de participación del Grupo surgen -a partir de las propias experiencias vitales de sus integrantes (Taller, 23 de octubre de 2010)- del cuestionamiento de las jerarquías patriarcales y las experiencias de izquierda ${ }^{27}$, derivando en la búsqueda de horizontalidad en las estructuras y la igualdad solidaria expresada en una remuneración igualitaria (Grupo Venancia, 2002, p.81). Ello no significa el desconocimiento de la existencia de cierta jerarquización de roles y protagonismos basada en el liderazgo informal y el compromiso desigual de las personas. Sin embargo, en la investigación se pudo observar que ésta era menor que la apreciada en otros espacios del movimiento feminista. Por otro lado, las Venancias reconocen que existe dentro del Grupo una hibridación de identidades entre ONG y colectivo, pero tratan de forma consciente y sostenida de preservar lo segundo (Grupo Venancia, 2002, p. 81) y no ser “capturadas" por las modas y discursos de la cooperación y el oenegenismo ${ }^{28}$.

El Grupo nunca tuvo un modelo fijo predeterminado de cómo participar

27 Una Venancia recuerda: "Yo venía de trabajar en el Ministerio de Salud y conocí muchos compañeros cubanos; aunque eran muy abnegados y preparados tenían una visión dogmática del proceso y la militancia revolucionarios que no era la nuestra" (L. Pérez, entrevista, 23 de octubre de 2010).

28 En esa dirección las Venancias deciden utilizar el término "contraparte" para las mujeres con que trabajan, pues sienten que la noción de "beneficiaria" lesiona su dignidad. Con premisas como ésta han desarrollado el trabajo en comuidades rurales, logrando impulsar la creación de otros grupos (Waslala) que tienen la meta de volverse, a su vez, autónomos (Grupo Venancia, 2002, p. 40).

29Como nos dice una protagonista, "Las Venancias funcionaron sin necesidad de formalizar una estructura. Ésta (con Asamblea y Junta Directiva) tuvimos que dárnosla a partir del gobierno de Alemán, ya que la legislación y la gestión de recursos nos la pedia)... la Junta es más formal, firma los documentos, etc... pero el poder está en la Asamblea y eso no lo queremos cambiar... también tuvimos que mejorar la organización para definir las responsabilidades y aumentar nuestro trabajo... yo, por ejemplo, soy profesional” (G. Gómez, entrevista, 22 de octubre de 2010). 
(Taller, 23 de octubre de 2010), sino que fue adecuándolo conforme aumentó la complejización del accionar después de $1998^{29}$, con el trabajo con mujeres rurales $^{30}$, la participación en el movimiento de mujeres, y el fomento de la capacitación, democracia y participación internas. Aparece la planificación anual y trianual, se formaliza y norma la membrecía del Grupo, se organizan tres equipos (Facilitación, Institucional y Comunicación) y tres comisiones para el trabajo interno (Recursos, Finanzas y Legal) en las que participan las trabajadoras, cooperantes y voluntarias (Grupo Venancia, 2002, pp. 38-39) innovaciones que les permiten ir paulatinamente delegando y descentralizando decisiones, lo que reduce frecuencia y duración de la coordinación, sin perder por ello el carácter colectivo y rotativo del involucramiento de las Venancias en las actividades del Grupo ${ }^{31}$ (Grupo Venancia, 2002, p. 82). Además, cada mes se efectúa una Reunión de Participación Política con todos los miembros, donde se realizan análisis de la coyuntura y propuestas de acciones (Taller, 23 de octubre de 2010), sirviendo como nexo con las iniciativas realizadas a partir de la participación personal de miembros del Grupo en otros espacios de mujeres (Grupo Venancia, 2002, pp. 50-51).

Pese a lo anterior, los recelos dentro del movimiento y las tentaciones (a veces inconscientes) de imponer o asumir un rol protagónico, pueden introducir tensiones en las redes. En 1996 los intentos del Grupo de reactivar la Red de Mujeres del Norte, con apenas un año de creada, generó recelos de otros colectivos a partir de lo que percibían como "protagonismo" de las matagalpinas. Aprendiendo la lección, las Venancias deciden convocar a la iniciativa a otras, viendo cómo la Red se fortaleció ${ }^{32}$ (Grupo Venancia, 2002, pp. 53-54). Una investigadora reconoce que "las Venancias han tenido la capacidad de incorporar nuevos miembros sin la agresividad de otras organizaciones; por ejemplo, el colectivo de Mujeres de Matagalpa -colectivo hermano de Venancias- tiene mujeres más comprometidas con el FSLN, con posturas tipo AMNLAE, y trabajan juntas en temas y acciones" (V. Delgado, entrevista, 25 de octubre de 2010), situación relevante dada la tirantez de los nexos al interior del movimiento de mujeres.

No obstante, es indudable que el entorno de polarización política actual ha afectado el trabajo desarrollado por el Grupo en su comunidad (Taller, 23 de octubre de 2010). Éste ha alcanzado hitos como, por ejemplo, cuando ante la devastación del huracán Mitch el Centro Guanuca devino durante tres meses albergue para más de 100 personas, involucrándose las Venancias en las actividades de protección civil a partir de su inclusión en el Comité de Emergencia Municipal, además de

30"Las Venancias se distinguen por su trabajo en temas de DDHH con mujeres rurales mientras otros grupos sólo apoyan el trabajo de las cooperativas. Eso es importante porque después de las elecciones de 2006 se pierde mucho vínculo con mujeres rurales y municipalistas por presiones partidarias" (V. Delgado, entrevista, 25 de octubre de 2010).

31 Enfatizan la necesidad de que todas incorporen como aprendizaje la importancia de una buena presupuestación y contabilidad, así como la preocupación por diversificar los fondos del Grupo, incluyendo la búsqueda de fórmulas autogestivas.

32 En esa dirección se ha dicho que "las Venancias han ganado respeto como espacio de consenso y mediación, que trata de distanciarse de las disputas dentro del movimiento de mujeres y asiste al esfuerzo de reconstrucción, pero sin olvidar lo que sucedió, sacando lecciones de eso" (F. Enriquez, entrevista, 23 de octubre de 2010).

33 Eso es reconocido por otras feministas que plantean: "Las Venancias, aunque replican estilos de liderazgo protagónicos en su localidad, tienen una capacidad y reflexión de medio nivel, y hacen un buen trabajo en su localidad" (M. M. Blandón, entrevista, 20 de octubre de 2010). 
ayudar a la ulterior rehabilitación de la devastada población de Waslala al construir junto a la comunidad y otras organizaciones 44 viviendas para los damnificados ${ }^{33}$ (Grupo Venancia, 2002, pp. 62-67). Sin embargo, bajo las nuevas directrices del Gobierno Nacional (establecer un modelo de participación controlado) el trabajo del gobierno local (cuyo alcalde fue innovador con políticas de participación en su gobierno anterior trabajando con los CDM, pese a críticas del FSLN ${ }^{34}$ ) da un giro, abandonando la colaboración con el Grupo, aunque sin reproducir las situaciones de violencia y acoso que se ven en otras ciudades (G. Gómez, entrevista, 22 de octubre de 2010).

\subsection{La cultura política de las Venancias}

Como sucede en todo grupo, la cultura de participación de las Venancias se ha formado a partir del entrecruzamiento de tradiciones previas (en ocasiones no democráticas), emergencias organizativas surgidas a partir del trabajo cotidiano, y la reflexión a partir de éstas. Como reconoce una protagonista: "al inicio teníamos la idea de construir un movimiento con mujeres y jóvenes rurales más horizontal, comenzamos con el grupo de capacitación, donde Helen y Yeta provenían de trabajar con UNAG y de las Madres de Mártires... ellas traían su propia cultura de la jefatura, aunque no sentías que te daban ordenes... yo venía de militar en el FSLN y trabajar en el Estado con el Movimiento Comunal (1989-1990), reforzando el trabajo comunitario para garantizar las tareas de la Revolución... al inicio no teníamos estructura, éramos pocas trabajando encima de un jeep... pero la idea siempre era funcionar como colectivo" (F. Enríquez, entrevista, 23 de octubre de 2010).

La idea de preservar el legado de la Revolución Sandinista, diferenciándolo de las actuales acciones del partido FSLN y su liderazgo, es notoria y obedece en buena medida al origen y militancia rojinegras de la mayoría de las Venancias. Una de ellas testimonia: "en nuestro Centro Cultural ofrecemos actividades como la Semana de la Revolución, donde analizamos el papel de la mujer para dar una mirada de dicho proceso más allá del FSLN y sus acciones actuales” (G. Gómez, entrevista, 22 de octubre de 2010).

Evidentemente los aprendizajes en torno a la participación dieron sus frutos en el marco de una reflexión colectiva que posteriormente ha sido sistematizada y difundida. En uno de sus textos, las Venancias enuncian un conjunto de características que definirían la democracia: unión de procedimiento e instituciones, práctica de libertad y justicia social, gobierno de mayorías con respeto a minorías y derechos individuales, elecciones libres y abiertas, descentralización, protección de DDHH, estímulo de participación, valores de tolerancia, colaboración y compromiso (Grupo Venancia, 2009, pp. 1-5). Con independencia del nivel desigual de asimilación/ contribución de las integrantes, la pesquisa nos reveló la existencia de un consenso y capacidad de análisis suficiente sobre los ejes y rasgos principales de la noción democrática (Taller, 23 de octubre de 2010).

En los textos producidos por el Grupo se visibiliza una capacidad de

34 "Las Venancias habian apostado desde el 2000 al trabajo local con la alcaldía del FSLN, pero ahora ese mismo alcalde no respondió a las expectativas" (V. Delgado, entrevista, 25 de octubre de 2010). 
análisis de la coyuntura (y de las estrategias para enfrentarla) poco frecuente en otros colectivos de similar tamaño y recursos. En sus documentos encontramos críticas a la transición al modelo neoliberal (1990) a partir de sus nocivos impactos en la vida cotidiana, en los cambios en el rol (cada vez más represivo) de la Policía, en la expansión del revanchismo y conservadurismo (machismo, homofobia) de derecha, mostrando claramente la mirada de izquierda del colectivo (Grupo Venancia, 2002, pp.13-15). Son notorias sus valoraciones a la visión de la presidenta Violeta Chamorro, convertida en una suerte de "gran ama de casa de la oligarquía, que buscaba manejar el país como una familia y combatir la pobreza con caridad cristiana" (Grupo Venancia, 2002, p. 35). Por su parte, el caudillo liberal Arnoldo Alemán es caracterizado repetidamente como un populista de derecha con un mensaje cargado de revanchismo antisandinista y un rechazo a las organizaciones sociales a las que veía simplemente como una "extensión del FSLN".

En otros textos es sostenida la crítica al pacto FSLN-PLC y su secuela de corrupción, ataque a instituciones y democracia, a las fraudulentas elecciones municipales de 2008 y a la creación de los CPC como espacios de cooptación y control oficial de la participación. También se analiza cómo las políticas de combate a la pobreza del actual gobierno (Hambre Cero, Usura Cero), si bien pueden aliviar las penurias acumuladas por años de neoliberalismo, no resuelven causas estructurales de la exclusión social y tienden a generar clientelismo, además de no poseer recursos para ser sostenibles (dependiendo de préstamos externos y cooperación venezolana) y servir de justificación para la violaciones de derechos cometida contra las voces críticas de la ciudadanía (Grupo Venancia, 2009, pp. 8-22).

\section{Conclusión.... sobre una lucha inconclusa}

Las poco más de dos décadas transcurridas de desarrollo histórico de la Nicaragua postrevolucionaria han estado marcadas por procesos contradictorios en los terrenos social, económico, político y cultural. La expansión del modelo neoliberal, con sus secuelas de empobrecimiento y desigualdad, vino de la mano con un fortalecimiento de las agendas y reformas institucionales y democratizadoras, impulsadas por asociaciones civiles y movimientos populares que, apoyadas por agencias de la cooperación internacional y algunos funcionarios, enfrentaron la oposición de los poderes fácticos (empresas, iglesias, medios) y las elites políticas tradicionales, tanto liberales como sandinistas. Dentro de estos actores prodemocráticos, interesados por conjugar las luchas tradicionales de la izquierda (justicia y desarrollo socioeconómico) con demandas democratizadoras (respeto al pluralismo y los derechos) destaca el beligerante y acosado movimiento de mujeres, cuyas luchas antipatriarcales y en defensa del derecho de las mujeres de disponer de su cuerpo y vida le han granjeado, alternativamente, el respeto y la animadversión de distintos sectores de la sociedad nicaragüense.

Un estudio atento de sus acumulados de luchas, propuestas y caídas nos alejará de las visiones románticas y simplificadoras. La articulación de una comprensión histórica de largo aliento con análisis situado de las experiencias particulares debe revelar, en lugar de la falsa imagen de un actor coherente y 
unitario, el caleidoscopio de una red de colectivos e identidades que se debaten entre la transformación de sus estructuras, dinámicas y culturas de participación o la reedición (dentro del movimiento) de los vicios de la política dominante que cotidianamente combaten. Los testimonios y la observación de las activistas y sus entornos revelan la persistencia, en el seno del movimiento y sus organizaciones, de identidades tradicionales (verticalistas, conspirativas, personalistas) heredadas del liderazgo revolucionario, que coexisten con el parto de nuevos modos de ser y relacionarse marcados por la horizontalidad y la diversidad como valores emancipadores.

La suma de luchas (parciales o articuladas) del movimiento de mujeres significa un legado inocultable al empeño por una Nicaragua más justa y democrática. Pese a temas pendientes y contradicciones, el haber plantado cara a todos los poderes seculares y los mitos enajenantes en dos décadas de predominio neoliberal y autoritario revela una mezcla de creatividad, persistencia y valentía encomiables y dignas de imitar por aquellos movimientos sociales nicaragüenses que quieran escapar del abrazo mortal de la política tradicional. De seguro "las generaciones venideras de la Nicaragua libre y luminosa" que nos anunciaba en su hermosa lírica aquel bardo rojinegro, tendrán mucho que agradecer al aporte de estas mujeres empeñadas en heredar a su descendencia un país más decente.

\section{Agradecimientos}

El autor agradece el apoyo de las personas e instituciones que hicieron posible esta investigación, en especial el Consejo Nacional de Ciencia y Tecnología (CONACYT) de México, el Instituto de Investigaciones Histórico Sociales de la Universidad Veracruzana, el Centro Interuniversitario de Estudios Latinoamericanos y Caribeños (CIELAC) de la Universidad Politécnica y el Instituto de Historia de Nicaragua y Centroamérica (IHNCA) de la Universidad Centroamericana. En particular agradece a todas las compañeras activistas de diferentes expresiones organizadas del movimiento de mujeres, por su testimonio y ejemplo.

\section{Entrevistas realizadas (por orden cronológico)}

Marta María Blandón: miembro y fundadora del movimiento de mujeres $(20 / 10 / 2010)$

Azahálea Solís: integrante del MAM (21/10/2010)

Filomena Enríquez: integrante del Grupo Venancia (23/10/2010)

Luisa Pérez: integrante del Grupo Venancia (23/10/2010)

Geni Gómez: integrante del Grupo Venancia (22 y 23/10/2010)

Taller \& Grupo de Discusión: integrantes del Grupo Venancia e invitadas $(23 / 10 / 2010$

Violeta Delgado: investigadora de CINCO (25/10/2010) 


\section{Referencias bibliográficas}

Alianza Feminista Centroamericana para la Transformación de la Cultura Política Patriarcal. (2010). Democracia en Centroamérica. Más mujeres en el poder, más hombres asumiendo las tareas domésticas, San Salvador: Alianza.

Arato, A. \& Cohen, J. (2002). Sociedad Civil y Teoría Política. México D.F.: Fondo de Cultura Económica.

Asamblea Nacional. (2010). Constitución Política de la República de Nicaragua. Recuperada el 10 de octubre de 2010, de http://www.asamblea.gob.ni/ opciones/constituciones/ConstitucionPolitica.pdf

ASDI/BID. (2006). Mapeo y Caracterización de las Organizaciones de la Sociedad Civil de Nicaragua. Informe preliminar. Managua:ASDI/BID.

Borchgrevink, A. (2006). Nicaragua: A Study of Civil Society. Norsk Utenrikspolitisk Institutt. Recuperado el 11 de octubre de 2010, de http://www.nupi.no/ content/download/637/13061/version/6/file/699.pdf

Cansino, C. (2010). La revuelta silenciosa. Democracia, espacio público y ciudadanía en América Latina. Puebla: BUAP/CEPCOM, Colección El Otro Occidente.

Chahim, D. \& Prakash, A. (2010). Grass without Roots. Foreign Funding and the Underdevelopment of Nicaraguan Civil Society. Recuperado el 2 de noviembre de 2010, de http://deanchahim.files.wordpress.com/2010/10/ chahim-prakash-arnova-2010-grass-without-roots_10-20-10.pdf

Chamorro, C. (2009). El “poder ciudadano” de Ortega en Nicaragua: ¿participación democrática, o populismo autoritario?. Recuperado el 10 de octubre de 2010, de http://www.wilsoncenter.org/events/docs/Chamorro.pdf

Chinchilla, N. (1994). Feminism, Revolution, and Democratic Transitions in Nicaragua en J. Jaquette (Ed.). The Women's Movement in Latin America: Participation and Democracy (2nd ed). (pp. 177-196). Boulder: Westview Press.

Coordinadora Civil. (2007). La Nicaragua que queremos desde la Coordinadora Civil (2007-2011) Recuperado el 10 de octubre de 2010, de www.ccer.org.ni/ files/doc/1202173987_Agenda__de_Nacion.pdf

Coordinadora Civil. (2009). Coordinadora Civil: Memoria, Desafíos y Retos Octubre 1998-2008. Managua: Coordinadora Civil.

Cruz, H. (2009). Los CPC en Nicaragua: un análisis sobre la articulación, el diseño la implementación del Poder Ciudadano. Recuperado el 15 de octubre de 2010, de http://hectormcruz.blogspot.com

Cuadra, E. \& Jiménez, J. (2009). El movimiento de mujeres y la lucha por sus derechos en Nicaragua: movimientos sociales y ciudadanía en Centroamérica. Managua: Centro de Investigación de la Comunicación.

Dagnino, E, Olvera, A. \& Panfichi, A. (coords.). (2006). La disputa por la construcción democrática en América Latina. México: Fondo de Cultura Económica/CIESAS/Universidad Veracruzana.

Domingues, J. M. (2009). La modernidad contemporánea en América Latina. Buenos Aires: CLACSO Coediciones/Siglo XXI.

Gertsch, E. (2010, 17 de mayo). De los CDS a los CPC. La Prensa. Recuperado 
el 10 de octubre de 2010, de http://www.laprensa.com.ni/2010/05/16/ politica/24768.

Grupo Venancia. (2002). Soñando lo imposible...haciéndolo posible. Once años de experiencia del Grupo Venancia construyendo en el feminismo entre mujeres. Matagalpa: Grupo Venancia.

Grupo Venancia. (2009). El Estado de la democracia en Nicaragua y nosotras las mujeres. Matagalpa: Grupo Venancia.

Kampwirth, K. (2009). Feminismo, antifeminismo y la lucha del aborto terapéutico. La memoria y consecuencias inesperadas de la revolución. En S. Martí \& D. Close (Eds.). Nicaragua y el FSLN 1979-2009 ¿Qué queda de la Revolución?. (pp. 83-115). Barcelona: Edicions Bellaterra.

Kinloch, F. (2008). Historia de Nicaragua. (3era ed.). Managua: IHNCA-UCA.

Montenegro, S., Cuadra, E. \& Saldomando, A. (2009). Nicaragua: entre la democracia y el autoritarismo. Managua: Centro de Investigación de la Comunicación.

Núñez, O. (2004). La Sociedad Civil. Managua: Universidad Centroamericana.

Núñez, O. (2007). El asalto al estado nacional. Recuperado el 5 de octubre de 2010, de http://www.radiolaprimerisima.com/noticias/17200

Prado, S. (2010). Libro Blanco de las relaciones estado-sociedad civil. Managua: Centro de Estudios y Análisis Políticos.

Prado, S. (2009). El modelo de organización y participación de la sociedad civil. ¿Qué aportó la cooperación internacional en los procesos de desarrollo tras el Mitch?. Recuperado el 5 de octubre de 2010, de http://archivo.ecodes.org/ pages/especial/mitch2009/doc/Silvio_Prado.pdf

Radio La Primerísima. (2007). Desde ayer, el CONPES está encabezado por la dirigencia nacional del FNT. Recuperado el 5 de octubre de 2010, de http:// www.radiolaprimerisima.com/noticias/13169

Serra, L. (2007). La Sociedad Civil Nicaragüense. Sus organizaciones y relaciones con el Estado, Managua: Universidad Centroamericana, Centro de Análisis Sociocultural.

Serra, L. (2010). El Comité de Desarrollo Municipal de Kukra Hill Una Experiencia de Concertación entre el Estado y la Sociedad Civil. Managua: Red Nicaragüense por la Democracia y el Desarrollo Local.

Silva, J. A. (2007, 30 de noviembre). Una funesta recurrencia histórica. El Nuevo Diario. Recuperado el 20 de octubre de 2010, de http://archivo.elnuevodiario. com.ni/2007/11/30/nacionales/65043

Stenber, K. (2010). NGOs and target groups in Nicaragua. A minor field study about grassroots effects of Professionalization. Recuperado el 10 de octubre de 2010, de http://vfsn.se/assets/files/Ovrigt/non_governmental_organizations.pdf

Svampa, M. (2008). Cambio de época. Movimientos Sociales y Poder Político. Buenos Aires: Siglo XXI.

Wheelock, J. (2007). Jaime Wheelock responde a Orlando Núñez. Recuperado el 10 de octubre de 2010, de http://www.radiolaprimerisima.com/noticias/17413 